\title{
Finding sense in new reality: from the epoch of machines to the age of uncertainty
}

\author{
Karel Slinták, Lucie Sára Závodná
}

\begin{abstract}
This paper deals with a new worldview. Using a historical analysis, this paper describes the original worldview in which the world is a mechanical universe, and puts forward a new worldview in which the world is a biological universe. The objective of this paper is to describe the change in the perception of the new worldview and to express the consequences of that change. It was discovered that important technological changes symbolize a new worldview and can also change this worldview. Information and biology became the fundamental impulses for the creation of a new view of the world. However, the world of organizations is still controlled by mechanical ideology which defines organizations as machines and maintains an economic environment based on a non-cyclical system. The new view of the world therefore requires this to change as it does the way we think.
\end{abstract}

Keywords: Biological society, epoch machines, information age, language of circle, linear thinking, language of line, sustainability, system thinking.

\section{Introduction}

At the time of the Industrial Revolution, the latest technical innovations were considered to be the source of wealth. In the past century, the productivity of an industrial worker was considered the primary source of wealth. Productivity based on scientific management was used to program workers to ensure that there was no deviation from the desired results [31]. Today, similarly as in the times of the Industrial Revolution, technical and technological innovations are believed to be the sources of all wealth $[9,15,27]$. The world is once again amazed by technologies. High-tech companies that produce unimaginable fortunes are standing at the forefront of these technological innovations. For example, the sales of Apple in Q2 2013 grew by 11\% to USD 43.6 billion, which is about three quarters of the state budget of the Czech Republic and one fifth of the country's GDP.

Drucker [30] states, that several centuries from now, scientists and historians will consider our era as not one in which the most important thing was new technologies, Internet and e-commerce, but an era in which people's lives changed and the fact that for the first time in history people had the possibility to choose between different options. For the first time people had to manage themselves in society, and society was simply not ready for this.

Today's society keeps following the paradigm of the industrial age $[14,66]$. This has not changed even though some observers have started pointing out that the era of machines is rapidly being replaced by the information age $[22,36,46,76,78,83]$. The human mind is subject to inertia.

Looking back we see that Cartesian philosophy with the revival of ancient Greek logic and the principle of causality stood at the birth of modern civilization. Descartes' ideas formed the theoretical basis for the study of reality. The first technical inventions based on a mechanical model of the universe gradually emerged from this base. The first one was Denis Papin's steam engine in approximately 1680 . An invention which was not to be built until thirty-two years later by Thomas Newcomen who installed a steam engine in one of the mining companies operating in England. Only one hundred years later, due to the invention of James Watt, mankind took advantage of a fundamentally different source of energy than animal muscle power, which until then had been the only widely used form of power. (The collar was probably invented by Benedictine monks in the tenth century in Europe. As a result, Europeans gained a new source of energy in the form of usable power from domesticated animals and within a very short time they caught up with China, a nation that was more advanced economically, socially and culturally). The invention of the railway (1829) and the construction of automobiles and aircraft followed at the end of the nineteenth century as means of transport based on technology created more than two centuries before by Denis Papin. The steam engine therefore became a symbol of the new era, the era of machines.

The twentieth century brought theoretical breakthroughs in physics by which mankind gained a new perspective for the assessment of objective reality. These were mainly ideas derived from Albert Einstein's theory of relativity - time and space is not fixed and absolute. These were followed by ground-breaking conclusions drawn from quantum mechanics, according to which one cannot say with certainty what (and what events) occur in the reality of the microworld (discovered by German physicist Heisenberg, this is known as the uncertainty principle). 
All these findings broke down the walls erected by Newtonian mechanics which described a predictable and essentially simple mechanistic universe.

The discovery of a new source of energy resulting from the splitting of atomic nuclei (the first controlled chain reaction was tested at the football stadium of the University of Chicago in 1942 by the Italian physicist Enrico Fermi) was the tangible result of the newly emerging world view. Finally in 1946, the construction of the first computer called ENIAC opened the door to the new age. However, it took forty years for the invention called the Internet to spread everywhere and for us to begin to talk about the information revolution under obvious economic and social changes.

Information has become a new source of wealth [27,75]. It has helped to develop new technologies and started changing the worldview to one that is conceived as a biological universe [26], one in which a new civilization is appearing.

\section{Methodology and objective}

This article aims to capture the fundamental change in perception and conception of the worldview. It focuses on the impact of this change on the perception of the external economic and social environment, looking at the impact of the new worldview on the systems we create in this environment. Using a historical analysis, the paper indicates the strength of the prevailing worldview and the way we understand the world around us. The conversion of the metaphysical environment (and its consequences) will be evaluated from different perspectives using the method of document collection. Time relations will be will be compiled using the method of analysis and synthesis and subsequently evaluated using historical analysis and the paradigm shift from a clockwork to the age of uncertainty.

\section{Results and discussion}

Mankind has undergone significant changes over the last four centuries. These changes were caused by initial impulses. Each of these impulses heralded a huge expansion of civilization and its creativity. Civilization has therefore developed in waves, as shown in Table 1, which led to two basic technologies based on mechanics and biotics.

Table 1

Major technological changes and their impact on the worldview

\begin{tabular}{c|ccc}
\hline Period & Civilizational change & First impulse & Worldview \\
\hline \multirow{2}{*}{1650} & Trade revolution & Ocean merchant ship & Paradigm of a clockwork \\
1712 & Industrial revolution & Steam engine & \\
1870 & Technical revolution & Car, plane, telephone, energy, & \\
& & steel, pharmaceuticals & Paradigm of uncertainty \\
\hline
\end{tabular}

According to Drucker [29] major technological changes always symbolize our worldview, as well as change this view. Technology based on a mechanical model of the universe which lasted approximately three hundred years (from the invention of the steam engine until the construction of the computer as the most elaborate of all machines which can express the analytical and conceptual side of things), was based on the paradigm of a clockwork. Technology based on the model of a biological universe was created only recently, less than seventy years ago. This worldview was derived from one of the most important discoveries of the twentieth century - the Heisenberg uncertainty principle. A new view of the world has therefore grown from the paradigm of uncertainty.

\subsection{Paradigm of a clockwork}

It was Stephen Covey [19], who compared the original economic environment to Newton's clockwork paradigm. Abiotic components, which are defined as inanimate parts of the environment which affect living organisms, have become an integral part of the environment. Based on the conceptual and analytical model, 
environment, organizations and individuals were recognized by the statement that the whole unit is equal to the sum of all its parts. Everything had to be examined rationally, understood, controlled and managed.

American writer and scientist Kevin Kelly [49] dealing with the biology of the business noticed that the mentioned ideology created the industrial model in which A leads to B, B leads to C, C leads to D and so on, ad infinitum. The whole procedure followed ancient Greek logic meaning that everything can be reduced to a strictly logical chain. In other words, all the actions were based on an analysis of the chain with the aim of detecting the primary cause. The environment was infiltrated with the causal principle. Knowledge in its most general form is therefore oriented towards the discovery of causation, not the purpose. This means that the character of the whole unit was always developed from the knowledge of its component parts. Furthermore, it was assumed that this could be achieved for all investigated phenomena (systems) without a difference. Today, we know that this approach, which is based on the method of classical mechanics, creates substantial limitations for knowledge. This is particularly true in biological systems where the whole unit is more than the sum of the individual parts. Therefore the original axiom $1+1=2$ is not correct.

Thinking is always based on social consciousness and a paradigm of the time. It can be understood in the sense of having a shared experience. The paradigm of a clockwork created people's ability to look at the outside world through the prism of static thinking $[12,80]$. Thinking shapes the language which we use for naming everything that surrounds us. Language forms our perception. The question is, what is a reflection of this perception?

For example, the linear economy [55, 68, 73, 52], hierarchical and bureaucratic organizations [53, 56], anthropocentrism [60], result in the systematic destruction of ecosystems and the unprecedented killing of animal species. These creations and attitudes of mankind show that we are still captives to the worldview of the past three centuries. As the result, we look at the world through the language of lines as described by Peter Senge [67]. He divides human perception into two basic categories using the languages of lines and circles. He believes that the only way to detect and understand the dynamics of today's world is through the language of circles. He describes the language of circles as a tool for understanding dynamic complexity whereby a change in one element affects all other elements and is also affected by them. Using the language of lines forces us to look at the world not as it is but as it should be according to us. It is obvious that with the wrong tools we cannot see the right image we are looking at, as is illustrated in Figure 1 below.

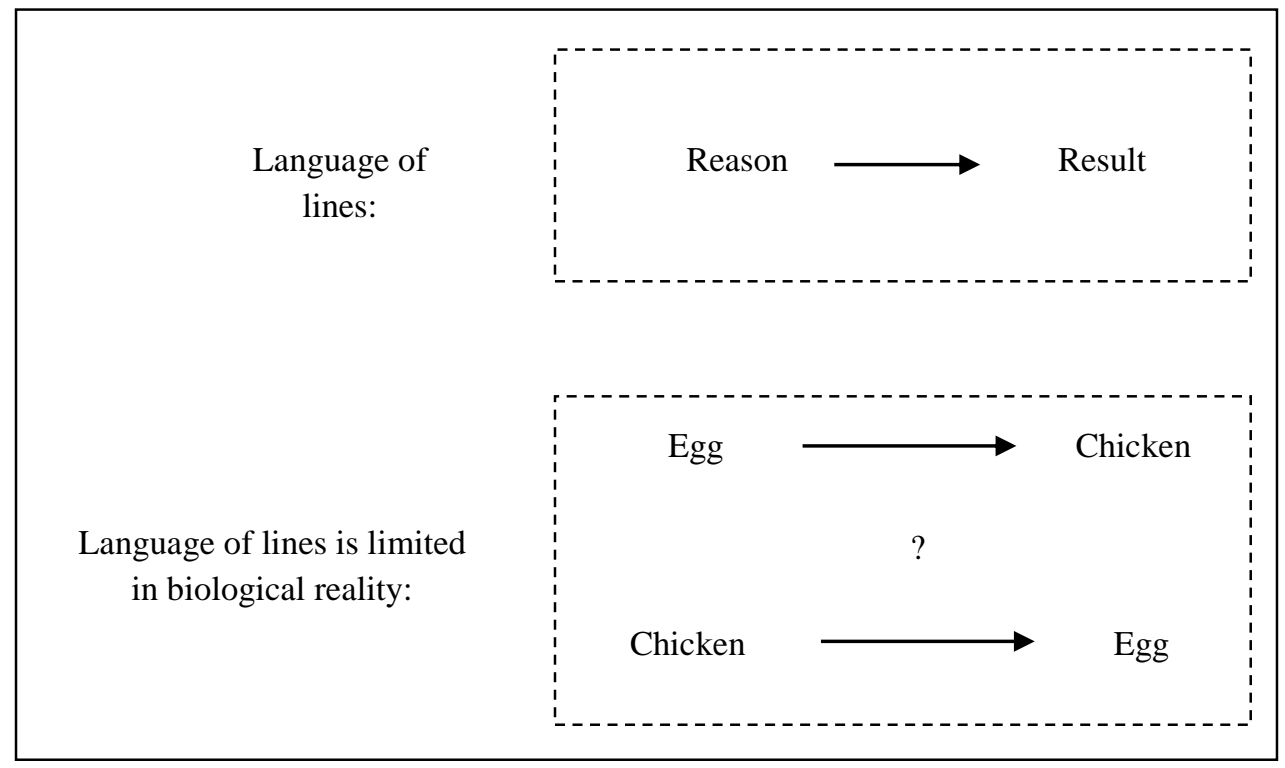

Figure 1. The limits of linear thinking

The special combination of ideology and technology, which results from linear thinking, defined the period when the first large enterprise organizations started (1870) and the actual arrival of the information era (beginning of the 1990s). As noted by Warren Bennis [10], the leaders of the twentieth century lived in this era in a much more linear world in which their organizations had a hierarchical and bureaucratic nature. This nature enabled them to make decisions in the technical-rational way. The evolvement of the environment was relatively stable, predictable and controllable. The changes occurred gradually and continuously [51]. The environment therefore could be relatively stable and slow moving.

The external environment was similar to the initial concept of computer technology in which you insert the relevant data and the system then generates a solution. These circumstances created a person's attitude towards the 
world (not only to the world of organizations) which was undoubtedly based on control, order and predictability. This was the right attitude in a stable environment in which you are largely able to control, dictate and predict.

The world of the last century was still under the impact of the ideas formulated in the seventeenth century despite the dawning of the age of uncertainty. The original environment was described as "mechanistic substrate", characterized by stability, linearity and predictability. These extremely reliable symbols of mankind's own existence were based on the philosophy of that period. The ideological basis of this period reflected determinism (according to Bauman [8]). Determinism is typical for a society of attribution, a society in which people but also the systems generated by them (e.g. organizations) are born in their identity without the opportunities of free choice and a conceptual and analytical approach to everything surrounding them. The motto for recognizing the world became Descartes' "cogito, ergo sum" a principle through which it was possible to map the landscape. The cognitive attributes of this principle are shown in the following table.

Table 2

Characteristics of the clockwork environment

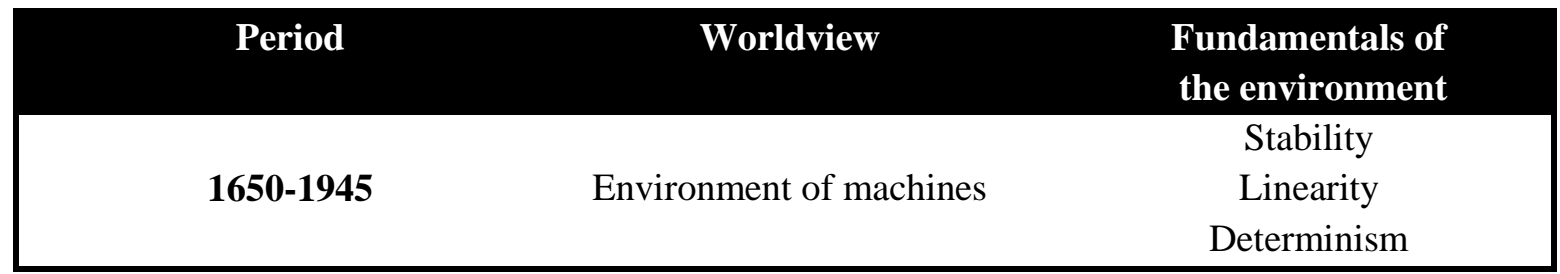

\subsection{Paradigm of uncertainty}

The original environment has changed. Symptoms and events in the real world no longer fall within the linear model [37]. The changes have become more substantial, widespread and last longer than ever before [22, 25]. At present, we have sufficient indisputable evidence that the very nature of the changes has changed. ${ }^{1}$ Change has become pervasive as well as constant. It has become customary [44]. Most organizations, however, ignore this fact (looking retrospectively into the Fortune 500 we find that from 1990 to 2000 approximately $40 \%$ of the largest organizations in the world closed down). The organizational environment has radically changed, in terms of customers, competitors and even the very nature of change.

The biggest impact on organizations has been the increasing pressure to disengage from the principles of traditional management. These principles formulated by Drucker $[29,31]$ as management paradigms no longer apply. It is a set of three premises that are a part of theoretical management and a set of four premises which create practical management. Drucker considers leaving these assumptions to be one of the most important management challenges of the 21st century. Enterprises enter the territory that Alvin Toffler [76] called "terra incognita", the uncharted land of tomorrow. According to Gibson [39] we open the gates of the nonlinear world. Everything around us becomes more complex and mutually dependent, and changes are increasingly nonlinear, disconnected and unpredictable. Collectively, we rush towards what some experts call the edge of chaos [39, 40, 57, 59]. The feeling of security is being replaced by a feeling of uncertainty. Our actions allow society to have its own mind [40]. Determinism is gradually replaced by free-will. In so doing, we are entering an age of unreason, a time when the future will in many ways be shaped by us and for us, a time when the only prerequisite that is confirmed is that no assumption will be confirmed. This will be a time that requires considerable imagination in private and public life and the ability to think about the unlikely and to do unwise things [41].

The deepening dynamics of the external environment caused by connectivity and interdependence accelerates the onset of an ecological era in which things are organized in a network rather than sequentially [63]. The forming non-biological civilization must therefore adopt completely new tools for exploring objective reality (namely

\footnotetext{
${ }^{1}$ As the evidence of this, we can consider the difficulty to predict development of the world economy, including crises, a high percentage of failed new projects (according to Harung [42] some empirical studies reported a $80 \%$ failure rate) and / or strategic planning process in companies, which was reduced from five and more years to the planning in the horizon of 1 year [69].
} 
causal field or causal circle). A new model for the conceptualization of the environment reflects its biological nature and takes many forms, such as intelligence or living organisms. The premise of the industrial age ${ }^{2}$ based on $^{2}$ the idea that the whole equals the sum of all the individual parts therefore loses its validity as the new ecological model emerges $[24,50]$. An analytical approach to things cannot therefore be exclusively used anymore. The new worldview and its assumptions, the most important part of which is that the whole equals more than the sum of the individual parts, enables us to see and understand the "whole" and assess the components only by perceiving the whole $[29,33]$. The fundamentals of the biological and information era reflect real life experience. When we look at team sports (e.g. tennis doubles), we marvel at how it is possible that two average players can as a team defeat two individually better players. In sport, this experience has established a new term called "mutual chemistry". Mutual chemistry marks the level of tuning of the individual components (elements) with the whole so as to achieve a synergic effect. The equation for synergy can be expressed as $1+1=3[2,20,21]$. This shift from analysis to configuration (i.e. specific arrangement of elements of the system) is most noticeable in various scientific disciplines. In all these disciplines, scientists learn terms ${ }^{3}$ such as autopoiesis $\left.[79,84,85]\right)$, immunity and homeostasis [43, 67], metabolism, model, symbiosis, synergy, which only a century ago would have been considered so radical that the expert community would have rejected them as offensive without any embarrassment. Each of these terms is not a description of some part (element) but rather reflects the integrity or behavioural structure of the phenomenon on the basis of mutual ties taking place inside the investigated system.

It is clear that this also affects the management of organizations. In the first half of the twentieth century, no one dared to speak in such terms as culture, integration, stakeholders, collective intelligence, feedback, processes and system archetypes. Today, on the contrary, we all talk about these in some form. Unconsciously we change causality for purpose. ${ }^{4}$ With new terms we gain the contours of the ecological model in which A leads to B, B leads to $\mathrm{C}$, however, where $\mathrm{C}$ leads to $\mathrm{A}$. Something unusual begins here. Circular causality appears $[6,11,18,38$, $47,48,61,62,65,70,71,77]$. Kelly [19] identifies it as self-causality and physicists who deal with quantum mechanics call it acausality. The new concept and perception mediates the world into interconnected nodes and networks in which we oppressively feel that they are not controlled by us. We experience a feeling of insecurity, a sense of interdependence, even a sense of relativity [23, 49].

The change of the order of things touches the very essence of humankind which is in today's world multidimensional (the paradigm of the holistic human shows four human dimensions - body, heart, mind and soul [20]). Due to the fact that we can do all things together - perceive, feel, think - but not just to think on its own (which was the preferred human dimension in the era of machines), we recognize the world in its wholeness. We are able to grasp the contemplative world if we utilise more dimensions of our brains than was the case in the past. The fundamental conversion of the environment requires a change away from strict, rational thinking. The key to a wider understanding of the world will therefore be the ability to learn a new language for the biological conception of reality. The desired language for these purposes appears to be a language that allows for the complete use of a human's personality i.e. those features which the renowned psychologist Carl Gustav Jung described in his works (Jung states that a person has four functions of personality: perception, intuition, thinking and feeling). A complex language for understanding reality is the language of interdependencies. The language of circles, as opposed to the language of lines, can describe the biological complexity with incredible beauty and simplicity.

The logical aporia of an egg and a chicken (and how it is resolved, as indicated in Figure 2), which cannot be resolved satisfactorily by the language of lines, as we have seen earlier, is drawn by the language of circles into a form that cannot be questioned. It shows the only possible answer due to the nature of the problem that is to be solved. In dynamic events, interactions cannot be captured by static tools. That is why this philosophical puzzle can only be captured by examining relationship - interaction, using the language of the relationship.

\footnotetext{
2 The premise of the industrial age, in fact, comes from a much earlier time. It is a fundamental axiom of classical arithmetic known since the time of ancient Greece (around 500 BC). At the end of the seventeenth century this assumption was legitimized by the French Academy in the sense that the whole is determined by its parts, so that the whole can be known only when we know its parts [28].

${ }^{3}$ These terms can be applied in the strictest Cartesian fields, including natural science at the forefront of physics. The most radical concept of contemporary scientists is quantum, based on suitably chosen unit (the so-called Planck's constant discovered in 1900), describes the separate energy flows at the level of elementary microparticles in such a way that substance and energy, space and time, position and momentum merge into a single natural variable, which has the character of further indivisible process.

${ }^{4}$ In the first half of the twentieth century, abstract art did not enjoy too much public interest. Today the work of abstract painters breaks records in sales, because it has changed the way people see not only art but the world as such. Previously, people were praising the art that mediated the view to the one who looked at them, while today we value of the art, which presents what the painter sees. Undoubtedly, it is more a sense than the description [33].
} 


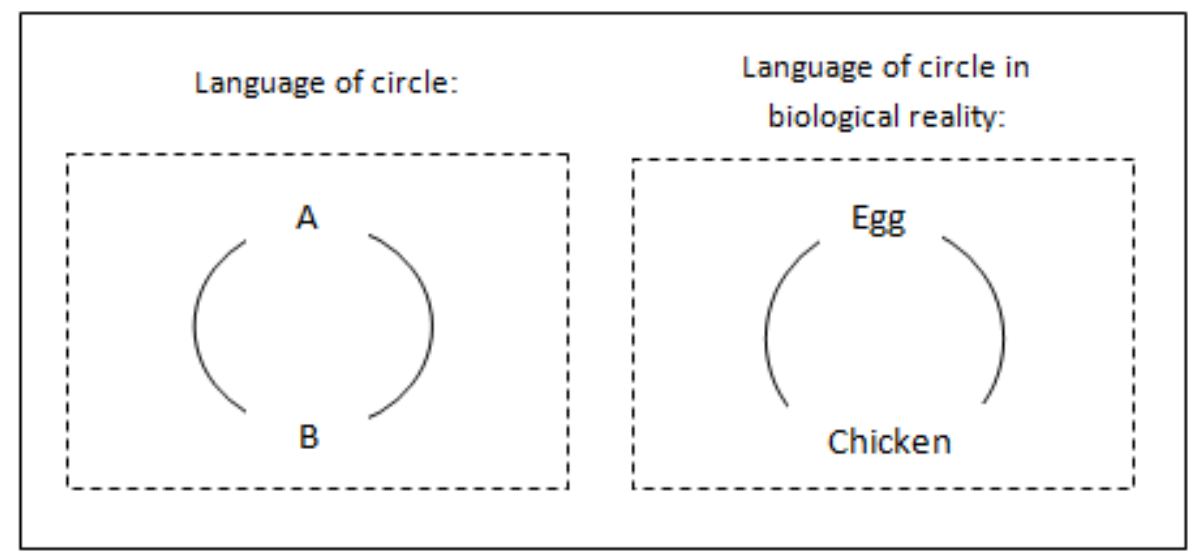

Figure 2. The range of circular thinking. Source: Adjusted according to [74].

A forming environment with dynamic complexity, interdependence and biodiversity calls for a new experience that follows on from the motto 'I think, therefore I am" which has been valid for more than three hundred years. This experience consists of the ability to conceptualize the world in its fullness. We must remember not only the motto "I think, therefore I am", but also "I perceive, therefore I am". ${ }^{5}$ The combination of the conceptual and perceptual aspects of the human personality will be the key to mastering the ability to systematically perceive reality. In the biological space, perception is the centre of everything. It is possible, or even a necessity, to train and develop it. We all know it subconsciously because we do not hear the "do-o-og" but only "dog". "Do-o-og", which has a nature of a bit, is a product of the analysis. It has a conceptual and analytical character but not a meaning. On the other hand, "dog" has the character of perception and is a product of thoughts and feelings that show the presence of holistic perception [33].

These findings obviously impact the world in which organizations live. In biology, there is a shift from analysis to perception. We can understand biology in the sense of living organisms and their ecosystems as well as in terms of organizations and their environment. In companies, but also in non-corporate institutions, dynamic plans that consist of several possible scenarios are being created. This is a thing which is rooted in perception rather than in analysis.

Table 3

Characteristics of the environment of uncertainty

\begin{tabular}{|ccc|}
\hline Period & Worldview & Fundamentals of the environment \\
\hline \multirow{2}{*}{$\mathbf{1 9 4 6}$ - today } & Environment of & uncertainty \\
& uncertainty & nonlinearity \\
& Free-will \\
\hline
\end{tabular}

Humans react to sudden, unexpected events like other animals. If we do not develop systematic thinking ${ }^{6}$, which is based on conceptual and perceptual thinking, we are not able to capture the gradual process of change [1, $4,5,13,16,17,54,58,67,74,86]$. While change in the past used to manifest itself discretely and continuously, in the current environment there is a continuous flow of changes that achieve exponential speed [45]. In such an environment we are, sooner or later, absorbed by the complexity of the things which we create.

The change which shapes the current environment stands on the pillars of complexity, discontinuity and nonlinearity i.e. elements responsible for the increasing dynamics of the external environment $[3,15,34,35,81$, 82]. These pillars convert the original mechanical substance of the external environment to the biological

\footnotetext{
${ }^{5}$ It is paradoxical that this view has already held by the Irish philosopher George Berkeley in the late seventeenth century. The result of his research in the theory of knowledge was famous Latin dictum "esse est percipi" (literally "to be is to be perceived"), by which he expressed its belief that the only possible knowledge is based on perception.

${ }^{6}$ Research carried out on young children shows that people have a latent ability to think systemically, however, the traditional education based on linear thinking does not develop (or even suppresses) these capabilities. [64]
} 
substance. Famous philosophers from the turn of the seventeenth and eighteenth centuries codified the prevailing worldview ${ }^{7}$ in terms of the mechanistic conception of the universe. The suggested transition from the mechanistic to the biological universe will therefore, sooner or later, need its own philosophical synthesis to define new areas of knowledge. These areas will be the basis for important scientific questions that will develop the characteristics of the environment (see previous table). This environment started to form itself at the end of the 1940s and continues to this day.

\section{Conclusion}

The structure of today's organizations undoubtedly reflects a worldview built on the idea of the mechanistic conception of the world. Organizations still perceive human beings by the paradigm of a fragmented man. In today's companies, as well as in those one hundred years ago, we can observe a strict division of labour, the principle of managing and controlling powers, intelligence concentrated at the highest levels of an organization, and a culture of politics and gossip. This is the concept of a mechanistic organization [85].

The ecosystem (or environment) of today's companies is reflected in the same spirit. It has been inherently the same since the industrial age. It is a non-cyclical system that floods the environment with difficult to digest waste and by its very nature threatens the delicate balance of nature.

From the ecological point of view, organizations and their ecosystems therefore face the problem of sustainability. There is no living creature with a non-cyclical character present in nature. The waste of one living system is a nutrient for another living system. This is the law of sustainability.

To paraphrase Gregory Bateson [7], the source of all today's problems is the difference between how we think and how nature works. The existence of "unlawful industrial systems" requires a fundamentally different view of the world. The aim of this paper was therefore to capture the newly emerging worldview which is penetrating today's reality - a new view of the world which is in stark contrast to the world of the past three hundred years. Until now it has been a very linear world in which continuity and stability were the norm. However, discontinuity and uncertainty are becoming the norm in today's world. We also need to realize that development, growth and change are real and normal, and that the absence of development, growth and change means destruction, decay and ultimate termination.

The technology of today's world has approached the biological nature and it largely changes one's view of the world. The new view shows the world in a broader context. The motto of the New Age, "Think globally, act locally", within the context of the new paradigm of uncertainty takes on a completely opposite meaning. We must therefore learn to perceive our own actions in terms of a flap of a butterfly's wings.

Simply said, the paradigm of uncertainty can't be understood according to thinking based on the language of lines.

\section{References}

[1] V. Anderson and L. Johnson, Systems thinking basics, MA: Pegasus Communications, 1997.

[2] I. H. Ansoff, Corporate strategy: An analytic approach to business policy for growth and expansion, Penguin books. 1970.

[3] B. W. Arthur, Complexity and the economy, Science, 284 (5411) (1999), 107-109.

[4] Z. B. O. Assaraf and N. Orion, System thinking skills at the elementary school level, Journal of Research in Science Teaching, 47(5) (2010), 540-563.

[5] Z. B. O. Assaraf and N. Orion, Development of system thinking skills in the context of earth system education, Journal of Research in Science Teaching, 42(5) (2005), 518-560.

\footnotetext{
${ }^{7}$ Worldview, describing the world as a mechanical universe, was set to a metaphysical system, which was created by a major German philosopher Immanuel Kant in the work entitled Kritik der reinen Vernunft (1781). This work was, however, significantly influenced by the ideas of David Hume, which were published in the book Enquiry concerning Human Understanding.
} 
[6] G. Bateson, Mind and nature: A necessary unity, New York: Dutton, 1979.

[7] G. Bateson, Steps To an Ecology of Mind, New York: Ballantine, 1972.

[8] Z. Bauman, The Art of Life. Praha: Academia, 2010.

[9] J. Beniger, The control revolution: Technological and economic origins of the information society. Harvard University Press, 2009.

[10] W. Bennis, Becoming a Leader of Leaders. In R. Gibson, Rethinking the future. Praha: Management Press, 2007.

[11] L. Biggiero, Managerial action and observation: A view of relational complexity. Biosystems, 22 (1998), 123-146.

[12] C. Bratianu, Thinking patterns and knowledge dynamics. In Proceedings of the 8th European Conference on Knowledge Management, Academic Conferences Limited, 2007.

[13] D. Cabrera, L. Colosi and C. Lobdell, Systems thinking. Evaluation and program planning, 31(3) (2008), 299-310.

[14] M. Carnoy, Sustaining the new economy: Work, family, and community in the information age. Harvard University Press, 2009.

[15] M. Castells, The rise of the network society: The information age: Economy, society, and culture, John Wiley \& Sons, 2011.

[16] P. Checkland, Systems thinking. Rethinking management information systems, 1999, 45-56.

[17] P. Checkland, From optimizing to learning: A development of systems thinking for the 1990s, Journal of the Operational Research Society, 1985, 757-767.

[18] B. Clemson, Cybernetics: A new management tool, CRC Press, 1991.

[19] S. R. Covey, The 7 Habits of Highly Effective People, Praha: Management Press, 2010.

[20] S. R. Covey, The 8th Havit. From Effectiveness to Greatness, Praha: Management Press, 2010.

[21] S. R. Covey, The 3rd Alternative: Solving Life's Most Difficult Problems, Praha: Management Press, 2013.

[22] S. Crainer, Key Management Ideas: Thinkers that changed the management world, Praha: Management Press, 2000

[23] R. Dai, Chaotic Order: A Consequence of Economic Relativity. In Complexity in Economics: Cutting Edge Research, 2014 (117135). Springer International Publishing.

[24] E. H. Daly and J. Farley, Ecological economics: principles and applications, Island Press, 2010.

[25] M. Davidson, Jak se stát skvélým stratégem. Praha: Management Press, 1997.

[26] J. S. Dick, The biological universe: The twentieth century extraterrestrial life debate and the limits of science. Cambridge University Press, 1999.

[27] A. T. Dillon, K. R. Lee and D. Matheson, Value innovation: Passport to wealth creation. Research-Technology Management, 48(2) (2005), 22-36.

[28] P. F. Drucker, A Functioning Society: Selection from Sixty-Five Years of Writing on Community, Society, and Polity, Praha: Management Press, 2004.

[29] P. F. Drucker, The Essential Drucker: In One Volume the Best of Sixty Years of Peter Drucker's Essential Writings on Management, Praha: Management Press, 2002.

[30] P. F. Drucker, Managing Knowledge Means Managing Oneself, Leader to Leader, 16 (2000), 8-10.

[31] P. F. Drucker, Management in a Time of Great Change, New York: Plume, 1998.

[32] P. F. Drucker, Managing for the future: the 1990s and beyond, New York: Truman Tally Books, 1992.

[33] P. F. Drucker, The New Realities, London: Heinemann Professional Pub., 1989.

[34] W. Elsner, The "new" economy: complexity, coordination and a hybrid governance approach, International Journal of Social Economics, 31(11/12) (2004), 1029-1049.

[35] H. J. Finch and M. Orillard, Complexity and the economy: implications for economic policy, Edward Elgar Publishing, 2005.

[36] C. Freeman and F. Louçã, As Time Goes By: From the Industrial Revolutions to the Information Revolution: From the Industrial Revolutions to the Information Revolution, Oxford University Press, 2001.

[37] C. Freeman, The greening of technology and models of innovation, Technological forecasting and social change, 53(1) (1996), $27-$ 39.

[38] R. M. Gardner and R. W. Ashby, Connectance of large dynamic (cybernetic) systems: critical values for stability, Nature, 228 (1970), 784.

[39] R. Gibson, Rethinking the future, Praha: Management Press, 2007.

[40] Ch. Handy, Finding Sense in Uncertainty, In R. Gibson, Rethinking the future, Praha: Management Press, 2007.

[41] Ch. Handy, The age of unreason, Harvard Business Press, 1990.

[42] H. S. Harung, Invincible Leadership, Praha: Euromedia Group, 2004.

[43] M. Hammer, The Agenda: What Every Business Must Do to Dominate The Decade, Crown Pub., 2003.

[44] M. Hammer and J. Champy, Reengineering the Corporation, Praha: Management Press, 2000.

[45] M. Hammer, Beyond the End of Management, In R. Gibson, Rethinking the future, Praha: Management Press, 2007.

[46] S. Inayatullah, Deconstructing the information era: Imagining a gaia of civilisations, Futures, 30(2) (1998), 235-247.

[47] A. J. Johanessen, J. Olaisen and B. Olsen, Systemic thinking as the philosophical foundation for knowledge management and organizational learning. Kybernetes, 28(1) (1999), 24-46.

[48] M. Kapsali, Systems thinking in innovation project management: A match that works, International Journal of Project Management, 29(4) (2011), 396-407.

[49] K. Kelly, The New Biology of Business. In R. Gibson, Rethinking the future, Praha: Management Press, 1997.

[50] K. Kelly, 1994, Out of control: the new biology of machines, social systems and the economic world, Basic Books, 1995. 
[51] J. P. Kotter, Leading change, Harvard Business Press, 1996.

[52] S. Lei and Q. Yi, Strategy and mechanism study for promotion of circular economy in China, Chinese Journal of Population Resources and Environment, 2(1) (2004), 5-8.

[53] R. Mansfield, Bureaucracy and centralization: An examination of organizational structure. Administrative Science Quarterly, 1973, 477-488.

[54] S. M. Manson, Simplifying complexity: a review of complexity theory, Geoforum, 32(3) (2001), 405-414.

[55] J. A. Mathews and H. Tan, Progress toward a circular economy in China, Journal of Industrial Ecology, 15(3) (2011), 435-457.

[56] M. E. McGill, J. W. Slocum Jr. and D. Lei, 1992, Management practices in learning organizations, Organizational Dynamics, 21(1) (1992), 5-17.

[57] B. McKelvey, Self-organization, complexity catastrophe, and microstate models at the edge of chaos, Variations in organization science: in honor of Donald T. Campbell, 1999, 279-307.

[58] M. Mulej, Systems theory: a worldview and/or a methodology aimed at requisite holism/realism of humans' thinking, decisions and action, Systems Research and Behavioral Science, 24(3) (2007), 347-357.

[59] R. T. Pascale, M. Milleman and L. Gioja, Surfing the edge of chaos, Sloan management review, 40(3) (1999).

[60] R. E. Purser, C. Park and A. Montuori, Limits to anthropocentrism: Toward an ecocentric organization paradigm?, Academy of Management Review, 20(4) (1995), 1053-1089.

[61] G. P. Richardson, Problems for the future of system dynamics, System Dynamics Review, 12(2) (1996), 141-157.

[62] B. Richmond, Systems thinking: critical thinking skills for the 1990s and beyond, System dynamics review, 9(2) (1993), 113-133.

[63] P. J. Robertson and T. Choi, Ecological governance: Organizing principles for an emerging era, Public administration review, 70(s1) (2010), s89-s99.

[64] N. Roberts, Teaching Dynamic Feedback Systems Thinking: An Elementary view, Management Science, 24(8) (1978), 836-843.

[65] F. L. Rupérez, Globalization and education, Prospects, 33(3) (2003), 249-261.

[66] J. L. Sampler, Redefining industry structure for the information age, Strategic Management Journal, 19(4) (1998), 343-355.

[67] P. Senge, The fifth discipline: The art and practice of the learning organization, Praha: Management Press, 2009.

[68] P. Senge and G. Carstedt, Inovating Our Way to the Next Industrial Revolution, Sloan Management Review, 42 (2001), 24-38.

[69] K. Slinták, The Principles of Biotic Organization: from performance to efficiency. Doctoral dissertation. Tomas Bata Univerzity, 2013.

[70] L. B. Smith and E. Thelen, Development as a dynamic system, Trends in cognitive sciences, 7(8) (2003), 343-348.

[71] R. D. Stacey, The science of complexity: An alternative perspective for strategic change processes, Strategic management journal, 16(6) (1995), 477-495.

[72] W. R. Stahel, The service economy: 'wealth without resource consumption'?, Philosophical Transactions of the Royal Society of London, Series A: Mathematical, Physical and Engineering Sciences, 355(1728) (1997), 1309-1319.

[73] W. R. Stahel, The functional economy: cultural and organizational change, The Industrial green game: implications for environmental design and management, 1997, 91-100.

[74] D. J. Sterman, Business dynamics, Columbus: McGraw-Hill, 2000.

[75] T. Stewart and C. Ruckdeschel, Intellectual capital: The new wealth of organizations, (1998), 56-59.

[76] A. Toffler, Powershift: Knowledge, Wealth, and Violence at the Edge of the 21st Century, New York: Bantam Books, 1991.

[77] B. Townley, Managing with modernity, Organization, 9(4) (2002), 549-573.

[78] M. Uhl-Bien, R. Marion and B. McKelvey, Complexity leadership theory: Shifting leadership from the industrial age to the knowledge era, The leadership quarterly, 18(4) (2007), 298-318.

[79] F. G. Varela, H. R. Maturana and R. Uribe, (1974). Autopoiesis: the organization of living systems, its characterization and a model, Biosystems, 5(4) (1974), 187-196.

[80] S. Vasilache, Evaluating Linear - Nonlinear Thinking Style For Knowledge Management Education Constantin BRĂTIANU, Management, 4(3) (2009), 3-18.

[81] J. Voge, The political economics of complexity: From the information economy to the 'complexity'economy, Information Economics and Policy, 1(2) (1983), 97-114.

[82] M. M. Waldrop, Complexity: The emerging science at the edge of order and chaos, Simon and Schuster, 1993.

[83] S. Wang, S., 1997, Impact of information technology on organizations, Human Systems Management, 16(2) (1997), 83-90.

[84] M. Zeleny, Autopoiesis and self-sustainability in economic systems, Human Systems Management, 16(4) (1997), 251.

[85] M. Zeleny, Self-organization of living systems: A formal model of autopoiesis, International journal of general system, 4(1) (1977), 13-28.

[86] U. Zoller, Environmental Education and the University: The Problem solving-decision making act within a critical system thinking framework, Higher Education in Europe, 15(4) (1990), 5-14. 


\section{Correspondence details and email address:}

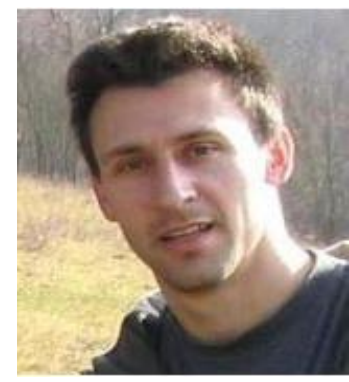

Karel Slinták (PhD, Tomas Bata University in Zlín, Czech Republic) is an academic and a researcher at the Faculty of Management and Economics. His research interests include management innovation, system theory and information system of organizations influencing their adaptability. Currently, he deals with trends in systems of management and examines selected firms aplying some elements of self-management. He is a member of a research project supported by Faculty of Management and Economics focused on social aspects of entrepreneurship.

Corresponding author:

Karel Slinták, Tomas Bata University in Zlín, Czech Republic, Tel.: +420 576032 512, E-mail:

slintak@fame.utb.cz

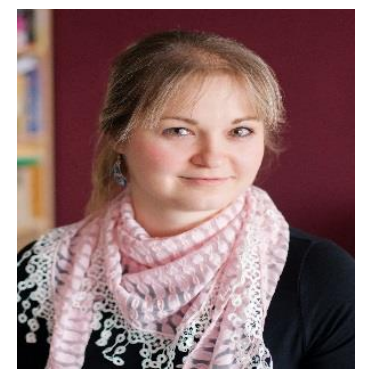

Lucie Sára Závodná (1984) has been a lecturer at Palacky University in Olomouc, Philosophical Faculty in the Czech Republic since 2012. She received two master degrees in Finance and Business Administration. Her Ph.D. is from Tomas Bata University in Zlin, Faculty of Management and Economics (Czech Republic). She has been studying and doing researches in Latvia (RISEBA, Riga) and Norway (NTNU, Trondheim). Research interests include tourism, new media, service sector and sustainability in different areas. She is authored the book "Sustainable tourism: Principles, certification and measurement" (2015) and co-authored the books "Media Education" (2010) and "How to Do Advertising" (2011). 